\title{
SURFACE INTEGRITY OF LM6 ALUMINUM METAL MATRIX COMPOSITE WHEN MACHINED WITH HIGH SPEED STEEL AND UNCOATED CARBIDE CUTTING TOOLS
}

\section{Mohd Hadzley Abu Bakar*, Raja Izamshah Raja Abdullah, Mohd Amran Md. Ali, Mohd Shahir Kasim, Mohd Amri Sulaiman, Siti Sarah Nadia Ahmad and Nurul Fatin Mohamad Raffi}

\author{
Faculty of Manufacturing Engineering, \\ Universiti Teknikal Malaysia Melaka (UTeM) \\ Hang Tuah Jaya, 76100 Durian Tunggal, Melaka, Malaysia \\ *Email: hadzley@utem.edu.my \\ Phone: +6063316446; Fax: +6063316418
}

\begin{abstract}
Metal matrix composite (MMC) is a combination of two or more materials in a metal matrix, and is being widely used nowadays due to its excellent properties. This paper presents the surface integrity of LM6 aluminum MMC when machined with two different cutting tools; high speed steel (HSS) and uncoated carbide. The experiments were carried out with a constant cutting speed, feed rate and axial depth of cut, but differ in the radial depth of cut under dry cutting conditions. Results indicated that machining LM6 with uncoated carbide cutting tools provides a lower surface roughness and fine surface profile compared to HSS cutting tools, due to its edge stability. A lower radial depth of cut produced a fine surface finish and vice versa. Most of the machined surface was dominated by the feed mark effect due to path overlap from the cutting tool. This study is expected to provide a database of suitable cutting tools and cutting parameters for machining MMC based materials.
\end{abstract}

Keywords: Machining; metal matrix composite; aluminum; surface integrity

\section{INTRODUCTION}

There are many metal matrix composites (MMC) on the market, such as aluminum MMC, magnesium MMC and titanium MMC. These MMCs have various properties depending on the shape, size, properties, volume fraction and distribution of the reinforcement material, properties of the matrix materials and compatibility of the matrix and reinforcement (Adebisi, Maleque, \& Rahman, 2011; Ala-Kleme, KivikytöReponen, Liimatainen, Hellman, \& Hannula, 2006; Bhaskar \& Sharief, 2012; Rahman, Kadirgama, et al., 2009). MMC generally consists of a light weight metal as the matrix element, and the fibers, whiskers or particles as the reinforcing element (Aeyzarq Muhammad Hadzreel \& Siti Rabiatull Aisha, 2013; Conceição António \& Paulo Davim, 2002). Zhang, Zhang, and Mai (1995) report that reinforcement enhances the properties of the structure produced by increasing the fracture toughness, resistance to high temperature, high strength-to-weight ratio, high stiffness and good damage resistance over a wide range of operating conditions, strength , and damage tolerance. The mechanical characteristics of the material can be altered by selecting the right matrix material and reinforcement material as well as the quantity to be embedded into the matrix. The machining of MMCs would be especially useful for manufacturing low 
volume custom or prototype parts, and in other applications requiring a complex shape and frequently modified designs (Chamber, 1996). According to Paulo Davim and Monteiro Baptista (2000), these unique properties have meant this material has potential as an alternative replacement for a wide range of products including jigs and fixtures, large holders, shock isolators, noise and vibration absorbers, seals, corrosion and abrasion protection, and electrical and thermal insulators.

The machining of MMC has been studied by several researchers. Ozben, Kilickap, and Çakır (2008) studied the mechanical properties and the effects of machining parameters on tool wear and the surface roughness of silicon carbide particulate $\left(\mathrm{S}_{\mathrm{i}} \mathrm{Cp}\right)$ reinforced aluminum MMC for different volume fractions. Alauddin, El Baradie, and Hashmi (1995) predicted the surface roughness of 190 BHN steel after end milling using a mathematical model depending on cutting speed, feed rate and depth of cut. Response surface methodology was used to investigate the effect of these parameters on surface roughness. A study by Suresh Kumar Reddy, Kwang-Sup, and Yang (2008) reported on the machinability of aluminum alloy reinforced with $\mathrm{SiC}$ using TiAlN coated carbide end mill cutters and its effect on surface integrity. The results show that the machinability in terms of both surface roughness and a lower tendency to clog the cutting tool improved with the presence of the reinforcement, when compared to a nonreinforced aluminum alloy. Arokiadass, Palaniradja, and Alagumoorthi (2011) studied the effect of spindle speed, feed rate, depth of cut and different $\%$ wt. of $\mathrm{S}_{\mathrm{i}} \mathrm{C}_{\mathrm{p}}$ on surface roughness by end milled aluminum MMC (LM25 Al/ $\left.\mathrm{S}_{\mathrm{i}} \mathrm{C}_{\mathrm{p}}\right)$.Previous research suggests that the machining of aluminum MMC is an apparently important area of research, but few studies have been conducted into the machining of LM6 aluminum MMC. This study focuses the effect of a radial depth of cut on the surface integrity of LM6 aluminum MMC by comparing the performance of two different cutting tools; HSS and uncoated carbide.

\section{EXPERIMENTAL WORK}

The workpiece material used in this study was LM6 aluminum MMC (LM6). The chemical composition for LM6 is shown in Table 1. The raw material was skimmed to remove any defects or irregularities on the surface from previous manufacturing processes. The new layer was then face milled and cut into the form of a $55 \mathrm{~mm} \times 55 \mathrm{~mm}$ $\mathrm{x} 40 \mathrm{~mm}$ block, as shown in Figure 1. Before machining, metallurgical samples were cut from the bulk material to understand the original microstructure of LM6. After cold mounting, grinding and polishing, an etchant solution was used to reveal the grain structure of LM6 using optical microscopy. The machining study was carried out in dry conditions on a HAAS' 3 axis CNC vertical milling machine VF-1. Back and forth milling strategy was developed for face mill operation. Two types of flat end mills were used: HSS and carbide (10mm diameter, $45^{\circ}$ helix angle and 4 flutes); as respectively shown in Figure 2(a) and 2(b)

Table 1. Chemical composition of LM6 aluminum MMC.

\begin{tabular}{llllllllllll}
\hline $\mathrm{Al}$ & $\mathrm{Cu}$ & $\mathrm{Mg}$ & $\mathrm{Si}$ & $\mathrm{Fe}$ & $\mathrm{Mn}$ & $\mathrm{Ni}$ & $\mathrm{Zn}$ & $\mathrm{Pb}$ & $\mathrm{Sn}$ & $\mathrm{Ti}$ & Other \\
\hline 85.95 & 0.1 & 0.1 & 12 & 0.6 & 0.5 & 0.1 & 0.1 & 0.1 & 0.05 & 0.2 & 0.2 \\
\hline
\end{tabular}




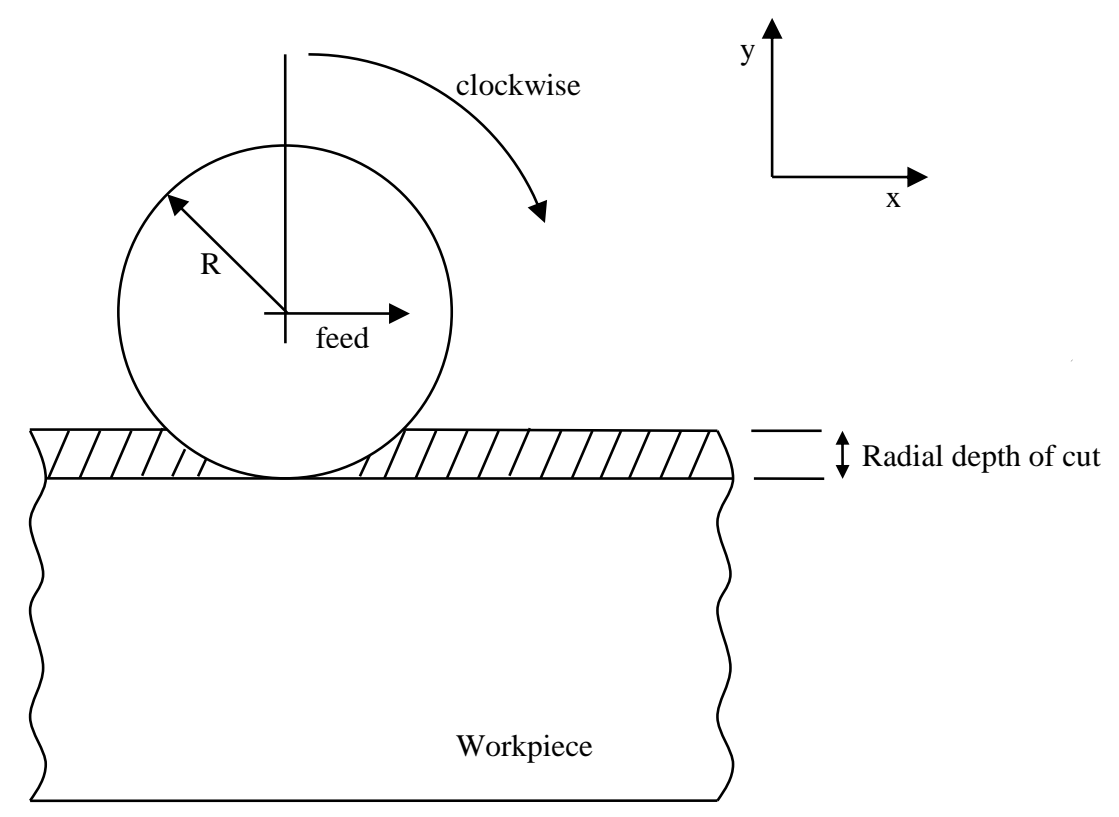

Figure 1. Schematic diagram of experiment.

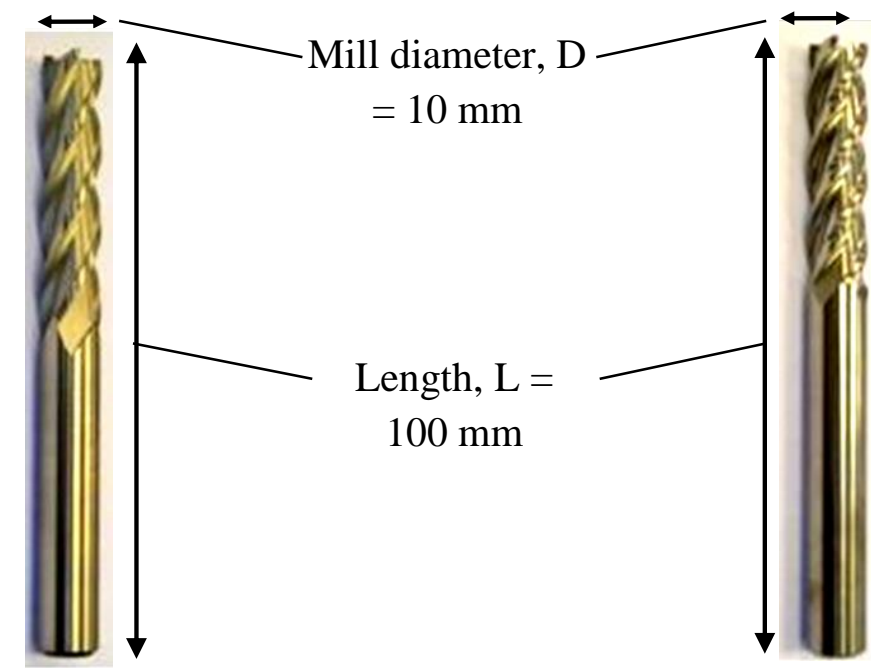

Figure 2. Type of cutting tools used; (a) HSS; and (b) Carbide

Milling experiments were carried out according to cutting conditions as shown in Table 2. A total of 10 experiments were conducted for each type of cutting tool by varying the radial depth of cut, from 0.01 to $0.10 \mathrm{~mm}$, based on finishing conditions of nominal aluminum alloy. Spindle speed, feed rate and axial depth of cut remained constant throughout the experiment. Machining time was recorded during machining. Surface roughness was measured using a Mitutoyo SJ-301 surface roughness tester three times at andom locations and the average value was calculated. 
Table 2. Milling conditions.

\begin{tabular}{ll}
\hline Parameter & \multicolumn{1}{c}{ Value } \\
\hline Spindle speed $(\mathrm{rpm})$ & 3000 \\
Feed rate $(\mathrm{mm} / \mathrm{min})$ & 60 \\
Axial depth of cut $(\mathrm{mm})$ & 0.5 \\
Radial depth of cut $(\mathrm{mm})$ & $0.01,0.02,0.03,0.04,0.05,0.06,0.07$, \\
& $0.08,0.09,0.10$ \\
\hline
\end{tabular}

\section{RESULTS AND DISCUSSION}

Figure 3 shows the microstructure of LM6 aluminum MMC observed under optical microscope (200x magnification). It shows that the crystal pattern of LM6 consists of a main structure with many appendages, which is called a dendrite. Dendrites are branching formations in which the crystals continuously grow, from a form of primary arm to secondary arm. $\alpha$-aluminum dendrites can be clearly observed. However, some of silicon particles present show the non-uniform casting process of the material due to a fabrication process that involves liquid aluminum which causes the migration of silicon (Lai \& Chung, 1994). This is an unavoidable nature of this material due to the processing technique.

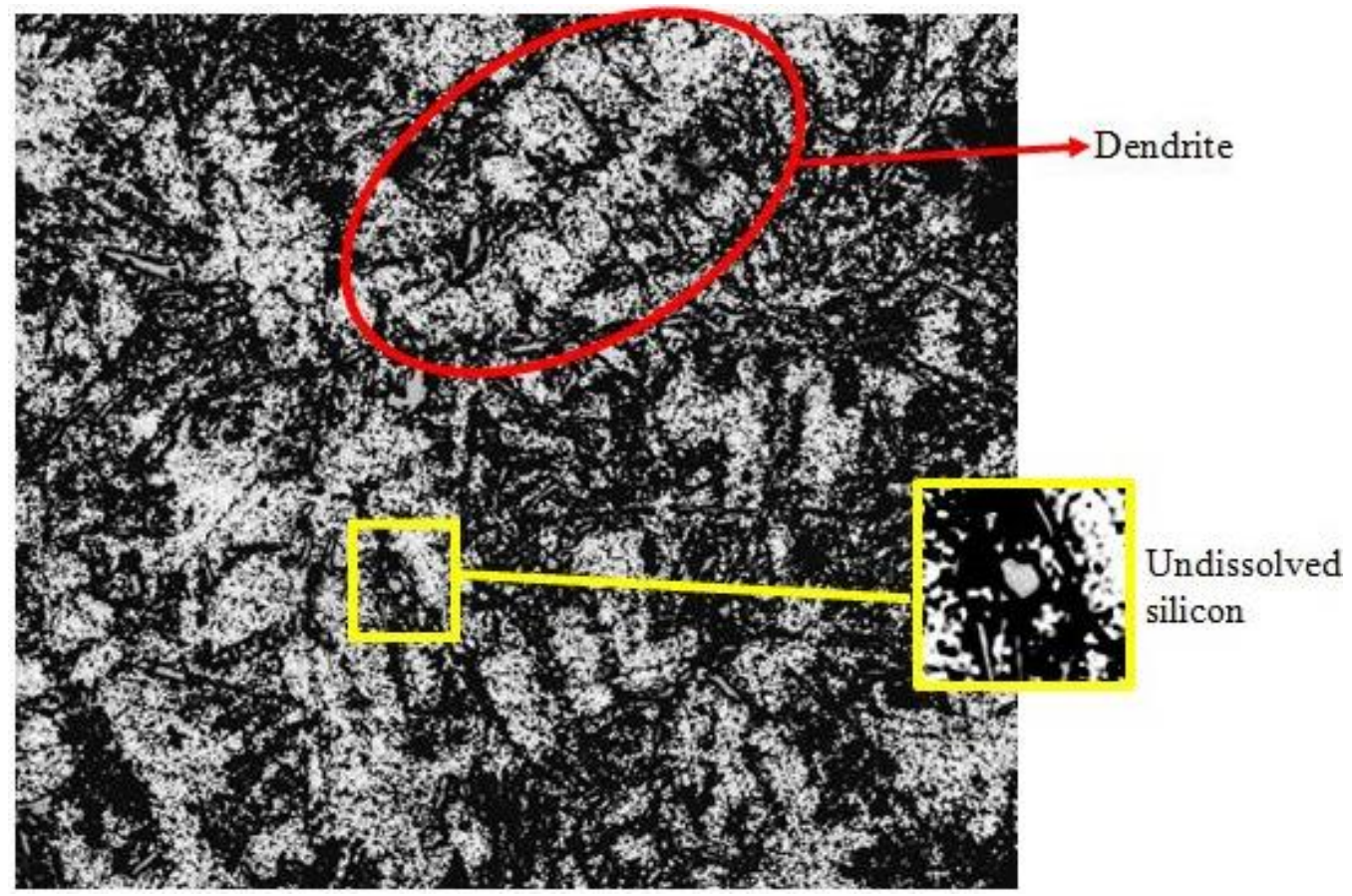

Figure 3. LM6 Aluminum MMC microstructure.

Figure 4 illustrates the trend of surface roughness when machining LM6 with HSS and uncoated carbide cutting tools at a rate-variant radial depth of cut. It generally shows that there are two regions of surface roughness recorded, an extremely high surface roughness value, around $1.45 \mu \mathrm{m}$ at $0.08-0.10 \mathrm{~mm}$ radial depth of cut and fine surface roughness value, around $0.11 \mu \mathrm{m}$ at $0.01-0.07 \mathrm{~mm}$ radial depth of cut. Most of 
the surface roughness values were less than $0.5 \mu \mathrm{m}$, which is considered acceptable with the quality almost equivalent to manual polishing (Baptista \& Antune Simões, 2000; Kadirgama, Noor, Rahman, Bakar, \& Hossein, 2009; Kadirgama, Noor, Rahman, Rejab, et al., 2009; Rahman, Khan, Kadirgama, Noor, \& Bakar, 2011). Both HSS and uncoated carbide cutting tools accomplished the best surface roughness of around $0.11 \mu \mathrm{m}$ when $0.01 \mathrm{~mm}$ radial depth of cut was used. However, it should be noted that machining at the lowest radial depth of cut of $0.01 \mathrm{~mm}$ required a long machining time of 292 minutes which does not comply with productivity requirements. The instability of the machining is obvious when a long machining time was taken to face milled the material. Taking machining time into consideration, the best cutting parameters obtained from the experiment were around $3000 \mathrm{rpm}$ spindle speed, $60 \mathrm{~mm} / \mathrm{min}$ feed rate and a radial depth of cut at $0.07 \mathrm{~mm}$.

Throughout the analysis, as seen in Figure 4, machining with an uncoated carbide cutting tool produced a slightly better surface finish, especially at $0.06-0.07 \mathrm{~mm}$ and $0.01-0.02 \mathrm{~mm}$ radial depth of cut. This is due to the edge stability during high speed machining. The uncoated carbide tool had better temperature resistance compared to HSS, which enables this cutting tool to perform better in the shearing process during machining LM6. HSS has low thermal softening properties, which make this cutting tool deteriorate easily within a short time. Dry cutting causes the temperature to be high which reduces the strength of HSS. The high temperature facilitates chemical reaction and intermetallic phases between tool and workpiece, and increases the friction which leads to an aggravated situation (Hogmark \& Olsson, 2005). Machining LM6 generally seems effective with an uncoated carbide cutting tool.

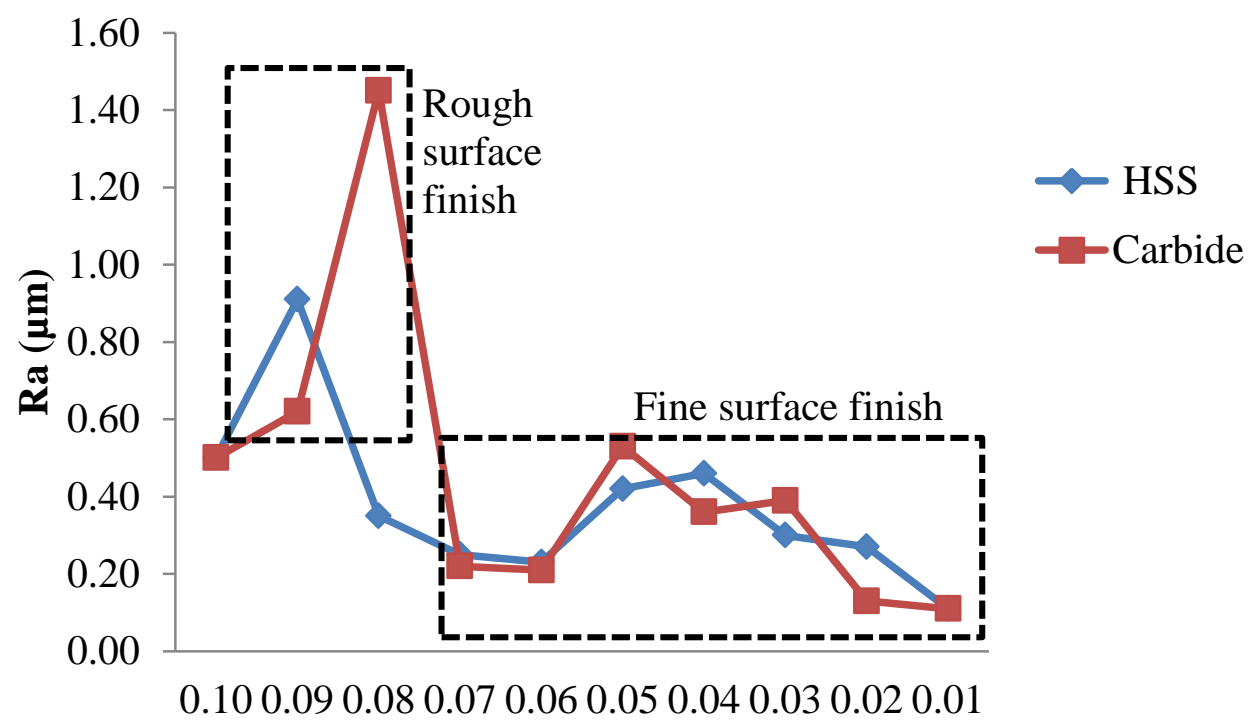

Radial depth of cut (mm)

Figure 4. Plot of surface roughness against radial depth of cut.

Figure 5 shows the surface profile of LM6 under investigation using both HSS and uncoated carbide cutting tools. The general profile of the machined surface consists of feed mark grooves in a direction according to the spindle rotation. These grooves are caused by the micro-shearing of the cutting edge. General examination of the machined surfaces for both cutting tools reveal the dependence of surface roughness on tool radius as well as on cutting parameters such as radial depth of cut and cutting speed. 


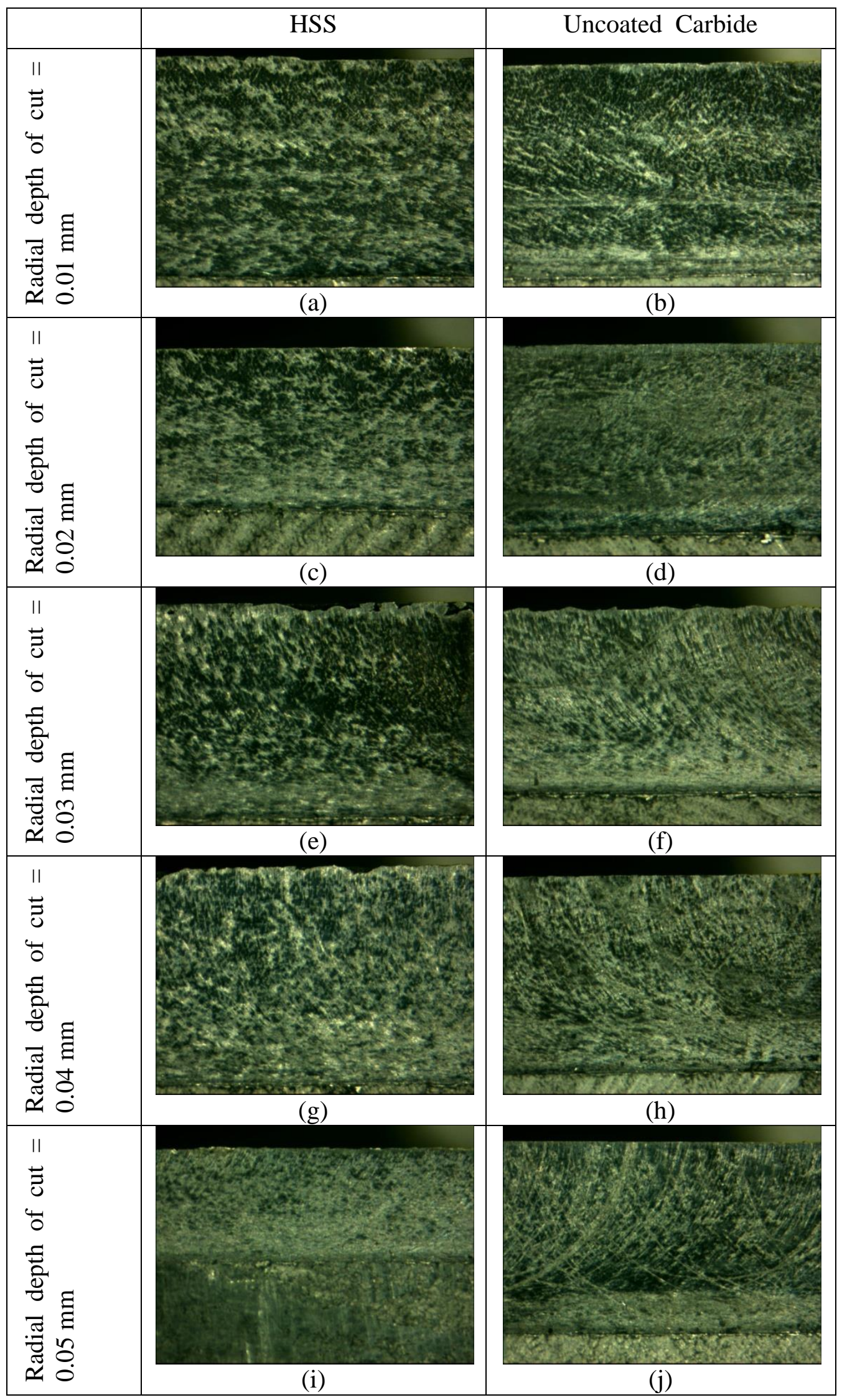

Figure 5. Surface profile of LM6 under investigation using both HSS and uncoated carbide cutting tools 
Despite the fact that a good surface finish was obtained using a small radial depth of cut, a close examination of the machined surface for both cutting tools shows that extensive surface smearing existed (Figure $5 \mathrm{a}-\mathrm{b}$ ). The fast spindle speed movement caused shearing of any surface that came into contact with the cutting tools, leading to obvious feed mark formation. Observation of the surface machined at a higher radial depth of cut revealed deterioration due to an increase in workpiece surface smearing, producing significant burrs on the feed mark ridges (Figure $5 \mathrm{i}-\mathrm{j}$ ). During this stage, the workpiece material in the cutting zone was subjected to high enough shearing and pressure to cause complete plastification. At the same time, high temperature development at the tool-chip interface formed a built up edge, leading to the deterioration of surface profile within a short time. Rahman, Khan, and Dhar (2009) found that shearing effect and plastic deformation cause heat generation at the primary deformation zone while secondary deformation and sliding cause heat generation at the tool-chip interface, and rubbing causes heat generated at tool-work interfaces. Since an uncoated carbide cutting tool has better stability at high temperature, this cutting tool has an added advantage, as the high temperature stability of the cutting tool will maintain the cutting edge in good shape during machining. This reduces friction due to a sharp cutting edge and minimizes heat transfer to the cutting tool; thus prolonging tool life and providing a better surface finish. Conversely, the HSS cutting tool is easily deformed compared to uncoated carbide under high temperature conditions. HSS cannot therefore withstand shearing force during machining; which makes this cutting tool easily too ductile, thus providing surface deterioration during shearing process.

\section{CONCLUSION}

The study indicated that surface roughness was directly proportional to radial depth of cut. A better surface finish was achieved as the radial of cut decreased. The best cutting parameters obtained from the experiment were a spindle speed of 3000rpm, feed rate of $60 \mathrm{~mm} / \mathrm{min}$ and radial depth of cut of $0.07 \mathrm{~mm}$ using an uncoated carbide cutting tool. Machining time was inversely proportional to radial depth of cut, however. Longer machining time was taken as the radial depth of cut decreased. High surface roughness (more than $0.5 \mu \mathrm{m}$ ) occurred because of the smearing effect in which the chip weld to the tool tip caused feed marks to form on the machined surface. Tool life could be considered in further study as a new part of this research, to consider the interaction between tool life and radial depth of cut using an HSS and carbide tool.

\section{ACKNOWLEDGEMENT}

The authors would like to thank the Universiti Teknikal Malaysia Melaka (UTeM) and the Malaysian government for facilities and financial support.

\section{REFERENCES}

Adebisi, A. A., Maleque, M. A., \& Rahman, M. M. (2011). Metal matrix composite brake rotor: Historical development and product life cycle analysis. International Journal of Automotive and Mechanical Engineering, 4, 471-480.

Aeyzarq Muhammad Hadzreel, M. R., \& Siti Rabiatull Aisha, I. (2013). Effect of reinforcement alignment on the properties of polymer matrix composite. Journal of Mechanical Engineering and Sciences, 4, 548-554. 
Ala-Kleme, S., Kivikytö-Reponen, P., Liimatainen, J., Hellman, J., \& Hannula, S.-P. (2006). Abrasive wear properties of metal matrix composites produced by hot isostatic pressing. Paper presented at the Proceedings of the Estonian Academy of Sciences, Engineering.

Alauddin, M., El Baradie, M. A., \& Hashmi, M. S. J. (1995). Computer-aided analysis of a surface-roughness model for end milling. Journal of materials processing technology, 55(2), 123-127.

Arokiadass, R., Palaniradja, K., \& Alagumoorthi, N. (2011). Effect of process parameters on surface roughness in end milling of al-sic mmc. International Journal of Engineering, Science and Technology, 4(1), 276-284.

Baptista, R., \& Antune Simões, J. F. (2000). Three and five axes milling of sculptured surfaces. Journal of materials processing technology, 103(3), 398-403.

Bhaskar, H. B., \& Sharief, A. (2012). Effect of solutionizing on dry sliding wear of al2024-beryl metal matrix composite. Journal of Mechanical Engineering and Sciences, 3, 281-290.

Conceição António, C. A., \& Paulo Davim, J. (2002). Optimal cutting conditions in turning of particulate metal matrix composites based on experiment and a genetic search model. Composites Part A: Applied Science and Manufacturing, 33(2), 213-219.

Hogmark, S., \& Olsson, M. (2005). Wear mechanisms of hss cutting tools. SME Technical Paper, 1-14.

Kadirgama, K., Noor, M. M., Rahman, M. M., Bakar, R. A., \& Hossein, A.-E. (2009). Fourth order torque prediction model in end milling Journal of Applied Sciences (Vol. 9, pp. 2431-2437).

Kadirgama, K., Noor, M. M., Rahman, M. M., Rejab, M. R. M., Haron, C. H. C., \& Abou-El-Hossein, K. A. (2009). Surface roughness prediction model of 6061-t6 aluminium alloy machining using statistical method. European Journal of Scientific Research, 25(2), 250-256.

Lai, S. W., \& Chung, D. D. L. (1994). Phase distribution and associated mechanical property distribution in silicon carbide particle-reinforced aluminium fabricated by liquid metal infiltration. Journal of Materials Science, 29(11), 2998-3016.

Ozben, T., Kilickap, E., \& Çakır, O. (2008). Investigation of mechanical and machinability properties of sic particle reinforced al-mmc. Journal of materials processing technology, 198(1-3), 220-225.

Paulo Davim, J., \& Monteiro Baptista, A. (2000). Relationship between cutting force and pcd cutting tool wear in machining silicon carbide reinforced aluminium. Journal of materials processing technology, 103(3), 417-423.

Rahman, M. M., Kadirgama, K., Noor, M. M., Rejab, M. R. M., Bakar, R. A., \& Harun, W. S. W. (2009). An experimental investigation into the effect of minimum quality lubricant on cutting temperature for machinability of aisi 9310 steel alloy. European Journal of Scientific Research, 29(4), 502-508.

Rahman, M. M., Khan, M. A. R., Kadirgama, K., Noor, M. M., \& Bakar, R. A. (2011) Optimization of machining parameters on tool wear rate of ti-6al-4v through edm using copper tungsten electrode: A statistical approach. Vol. 152-153 (pp. 1595-1602).

Rahman, M. M., Khan, M. M. A., \& Dhar, N. R. (2009). An experimental investigation into the effect of minimum quality lubricant on cutting temperature for machinability of aisi 9310 steel alloy. European Journal of Scientific Research, 29(4), 502-508. 
Suresh Kumar Reddy, N., Kwang-Sup, S., \& Yang, M. (2008). Experimental study of surface integrity during end milling of al/sic particulate metal-matrix composites. Journal of materials processing technology, 201(1-3), 574-579.

Zhang, Z. F., Zhang, L. C., \& Mai, Y. W. (1995). Wear of ceramic particle-reinforced metal-matrix composites. Journal of Materials Science, 30(8), 1961-1966. 